\title{
Updating urban forest inventories: An example of the DISMUT model
}

\author{
C.L. Brack* \\ School of Resources, Environment and Society, Australian National University, Canberra, Australia
}

\begin{abstract}
Canberra is a unique city in Australia where the trees on public land that dominate the urban forest were planned for at the city's inception. In the mid-1990s, a 100\% census of street and park trees was completed, and together with simple health, growth and yield models, this database formed the basis of a decision information system to support the management of the urban trees - DISMUT. The accuracy of the models was evaluated in a study in 2005 where models to predict total tree height were found to be unbiased and precise, tree crown dimension were under-estimated for small trees, and tree health was over-estimated. The over-estimate of health may be due to the relatively poor rainfall conditions over the past 10 years while the biases in crown dimension predictions are more likely due to a too simple model form. However, the existence of DISMUT predictions over all streets and parks in Canberra means that statistically efficient two-phase sampling approaches can be used to correct for any bias in the mean estimates of tree numbers and size, and also to predict the mean value of other environmental, economic or social parameters of interest that are correlated to tree size.
\end{abstract}

(C) 2006 Elsevier GmbH. All rights reserved.

Keywords: Two-phase sampling; Growth models; Health models; Urban forest management

\section{Introduction}

Canberra, the National Capital of Australia, is a city of over 300,000 people living in a well-treed and spacious environment. The urban forest of this city has undergone several distinct, but overlapping development periods, and today is a magnificent example of what can be achieved with holistic landscape planning (Banks and Brack, 2003). Trees on public land dominate the urban forest and provide a wide range of environmental, economic and social values (Brack, 2002). However, the forest is very dynamic with a diverse mixture of species, longevity and age classes, and resources for management are under increasing scrutiny even as management becomes increasingly complex.

\footnotetext{
${ }^{*}$ Tel.: + 61261253535 ; fax: + 61261250746 .

E-mail address: cris.brack@anu.edu.au.
}

Systematic collection of information is a common management reaction to perceived shortages of available resources (Brack, 1997), and in the 1990s development of a system to collect information to support urban forest management for Canberra was begun. The resulting system - Decision Information System for Managing Urban Trees (DISMUT) - was primarily designed to assist in planning urban forest asset management on public land. The census and modelling approach used in DISMUT to collect detailed information about urban forests in Canberra is different to most reported urban forest inventory systems, which include ground-based (random or systematic) samples of less than $10 \%$ of the urban area, or remote sensing of tree canopy with (occasionally) double sampling to statistically relate canopy dimensions with important tree parameters (Miller, 1988; Jaenson et al., 1992; Nowak et al., 1996; McPherson et al., 1997; Chen and Jim, 2003; 
Nowak et al, 2004). The DISMUT census was relatively inexpensive with a tally of the number of trees by species (or genus for less common trees) and visual health class collected as a vehicle travelled slowly along each street in the city. However, like the other approaches, there is a significant effort involved in the initial data capture and an economic incentive to allow inventories to be cheaply updated rather than repeated, and where appropriate to refocus the population parameter estimates to account for new questions and management needs.

This paper presents the outcomes of a study undertaken in the year 2005 to verify DISMUT and update tree health and size estimates. The paper also discusses the potential for efficiently deriving or updating estimates for a variety of urban forest parameters.

\section{DISMUT}

The DISMUT system comprises data from a $100 \%$ census of trees planted on public land in streets and "mown" parks and a series of growth and health models within a planning information system (Banks et al., 1999; Brack et al., 1999a, b; Brack and Banks, 2001; Brack, 2002). The tree census was undertaken between 1995 and 1999 by students and staff of the Department of Forestry, Australian National University. The data collected during the census included the species, age, and health for about 400,000 trees planted on public land in streets and parks, even where private individuals planted these trees. The growth models (or yield equations) were developed to predict the total height, maximum crown width and height of the maximum crown width for each species group (taxa) at any nominated age, but were biased towards trees more likely to trigger maintenance operations, i.e. larger-sized trees in each street and park. The health models predicted the probability that any tree, by taxa, will survive one more year without showing visible signs of stress or poor health. Inventory and models were thus developed to predict the likely areas, timing and cost of tree maintenance and management. For example, the location, timing and resources required to prune trees to ensure unrestricted access along streets and driveways could be predicted and planned.

DISMUT models the height and crown dimensions of the tallest trees in the street or park because these are strongly related to the timing and cost of maintenance, e.g., if the tallest tree requires a high-lift tower for crown repair work, it is likely that this equipment will also be used to treat other trees in the street while it is there. Mean height and crown dimension, however, may be more important when predicting the environmental, aesthetic or amenity values and a correction between maximum and mean values would be desirable.

\section{Methods}

A systematic sample of streets covering all Regions of Canberra and all taxa that represented more than $3 \%$ of the public urban forest estate was drawn from the DISMUT database. Sampling was stratified to ensure the inclusion of "healthy" streets where the probability of visible stress/poor health times the number of trees in the street was less than one (i.e. unlikely any trees were showing poor health) and "less healthy" streets where the probability times the number of trees was more than 5 (i.e. likely that the street included several unhealthy or stressed trees, and/or maintenance work may have been necessary since census). A list of 71 potential streets was forwarded to the appropriate land managers to determine whether work had been carried out on these sample streets or whether there were mitigating circumstances that meant the sample was non-representative. None of the streets were rejected from the potential sample list; however, due to time constraints the number of streets finally selected was only 45 . These 45 streets covered the full range of health classes and taxa and were sufficient to make statistically significant conclusions.

The health of all trees in the sample streets was classified using the DISMUT categories. These data were compared, on a street basis with the DISMUT predictions of healthy and unhealthy streets. In addition, about ten trees of the targeted taxa on each sample street, systematically selected over the whole street, were measured for total height, crown dimensions and bole diameter. A criterion laser was used to measure height and canopy dimensions (accuracy $\pm 1 \%$ for height, $\pm 5 \%$ for diameter) and a girth tape used for bole diameter. The street-based maximum and mean tree was determined for height and maximum crown width and compared with the 2005 DISMUT projections of the maximum values by taxa for the street.

\section{Results}

Over $50 \%$ of the original sample streets had been subject to reactive maintenance work (ignoring trees pruned or removed for non-health related reasons, e.g., development of new driveway), i.e. residents had complained about a tree and the appropriate land management agency had reacted with pruning, removal or other treatments. There was a significant relationship $(p<0.05)$ between DISMUT predictions of poor health and reactive work - less than one-third of streets where DISMUT predicted there would be no unhealthy trees had records indicating work had been carried out to treat some unhealthy trees; however, more than twothirds of streets where DISMUT predicted the presence of unhealthy trees did have reactive work (Table 1). 
This means that streets where DISMUT predicted the presence of unhealthy trees had twice the chance of requiring work by the land management authorities to treat stressed or unhealthy trees. Location (by city zone) or taxa was not significant.

Total tree heights ranged between 5 and $27 \mathrm{~m}$, while maximum canopy width varied between 4 and $26 \mathrm{~m}$. The regression between DISMUT predictions and maximum tree height was strong $\left(r^{2}=0.74\right)$ and not significantly different from a straight line with zero intercept and a slope of one (Fig. 1a). Point 12 represents a stand of Eucalyptus viminalis on the verge of a well-watered park. Two streets represented by point $15 \mathrm{had}$ an actual age of

Table 1. Contingency table of DISMUT health status prediction for streets in 2005 against reactive work in past 5 years (from the potential sample of 71 streets)

\begin{tabular}{|c|c|c|c|}
\hline $\begin{array}{l}\text { DISMUT } \\
\text { prediction of } \\
\text { street health }\end{array}$ & $\begin{array}{l}\text { No reactive } \\
\text { work } \\
\text { recorded }\end{array}$ & $\begin{array}{l}\text { Reactive } \\
\text { work } \\
\text { documented }\end{array}$ & Total \\
\hline $\begin{array}{l}\text { No unhealthy } \\
\text { trees in street }\end{array}$ & $\begin{array}{r}19 \\
27 \%\end{array}$ & $\begin{array}{r}8 \\
11 \%\end{array}$ & $\begin{array}{r}27 \\
38 \%\end{array}$ \\
\hline $\begin{array}{l}\text { Unhealthy } \\
\text { trees present }\end{array}$ & $\begin{array}{r}14 \\
20 \%\end{array}$ & $\begin{array}{r}30 \\
42 \%\end{array}$ & $\begin{array}{r}44 \\
62 \%\end{array}$ \\
\hline Total & $\begin{array}{r}33 \\
47 \%\end{array}$ & $\begin{array}{r}38 \\
53 \%\end{array}$ & $\begin{array}{r}71 \\
100 \%\end{array}$ \\
\hline
\end{tabular}

a) Maximum total height

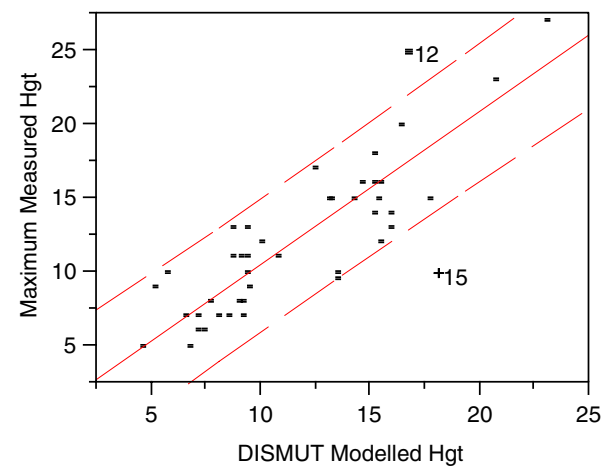

Summary of Fit

$R^{2}$

$R^{2}$ Adj

Root Mean Square Error

Mean of Response

Observations

Parameter Estimates

$\begin{array}{lrrr}\text { Term } & \text { Estimate } & \text { Std Error } & \text { Prob }>|t| \\ \text { Intercept } & 0.075 & 1.172 & 0.9493 \\ \text { DISMUT Hgt } & 1.037 & 0.094 & <.0001\end{array}$ planting that was much younger than the assumed age in DISMUT. These two points were removed from further analysis.

The regression between maximum crown width measured and predicted by DISMUT was much poorer $\left(r^{2}=0.35\right)$ but still significant (Fig. 1b). Some of the variation in the relationship may be due to measurement error, particularly where the tree crowns were irregular or partially obscured by other canopies. There is also an indication of bias with smaller canopies being underestimated by DISMUT.

The residuals for both these regressions were homogeneous and not significantly different to a normal distribution. Taxa was tested as a nominal variable and was not significant for either model.

Approximately $30 \%$ of the sample streets had substantially more trees than recorded in DISMUT, which appeared to be the result of new leaseholder planting within the last 5-10 years or differences in the inclusion of park and leasehold land between the original census and this current study. To avoid confounding the testing of the model predictions with mapping and new planting errors, these observations were excluded from further analysis. Comparison of the various DISMUT stress classes was complicated by the possibility that trees could move between stress classes and that severely stressed trees could be felled, including stump grinding, thus removing all evidence of their existence from the survey. Consequently, a comparison

\section{b) Maximum crown width}

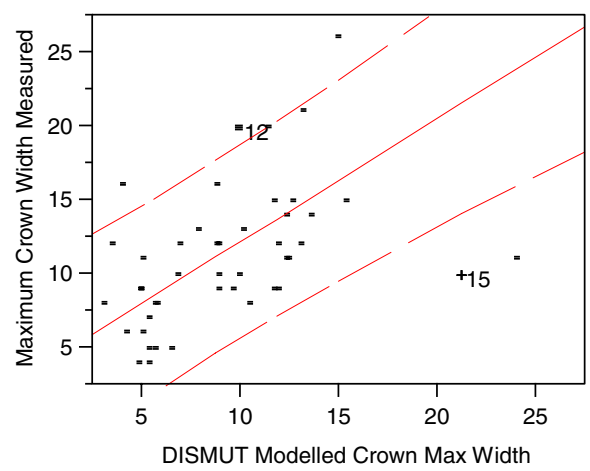

\section{Summary of Fit}

$\mathrm{R}^{2} \quad 0.365$

$\mathrm{R}^{2}$ Adj $\quad 0.349$

Root Mean Square Error $\quad 3.837$

Mean of Response $\quad 11.19$

Observations 43

Parameter Estimates

$\begin{array}{lrrr}\text { Term } & \text { Estimate } & \text { Std Error } & \text { Prob }>|t| \\ \text { Intercept } & 3.851 & 1.621 & 0.0223 \\ \text { DISMUT Crown } & 0.832 & 0.172 & <.0001\end{array}$

Fig. 1. Scatter plot of DISMUT model predictions against measurements of the tallest trees in the sampled streets. Solid line denotes best fit, dashed lines denote the confidence $(p=0.1)$ range for individual estimates. 
between the numbers of trees/street predicted by DISMUT as healthy (no visible sign of stress) was compared with the number observed (Fig. 2).

The regression between DISMUT predictions of the number of healthy/non-stressed trees and the number observed in the sampled streets was strong $\left(r^{2}=0.87\right)$ and although the intercept was not significantly different to zero $(p>0.05)$, the slope was significantly less than one $(p<0.05)$, which indicates a bias in the predicted number of healthy trees (Fig. 2). Point 46 was examined but not found to be an influential point and was not removed. The regression residuals were not heterogeneous or significantly non-normal, and nor was taxa found to be significant.

\section{Discussion}

Figs. 1 and 2 demonstrate that DISMUT predictions of tree dimensions and health are significantly related to observations 5-10 years after the initial census data. Maximum height of trees in the street is unbiased and relatively precisely estimated by the DISMUT models, but there are apparent biases with crown dimensions and health/stress predictions. An absence of about $15 \%$ of healthy trees as predicted by DISMUT was approximately constant across all major taxa and age classes. Despite this bias in estimating healthy trees, streets

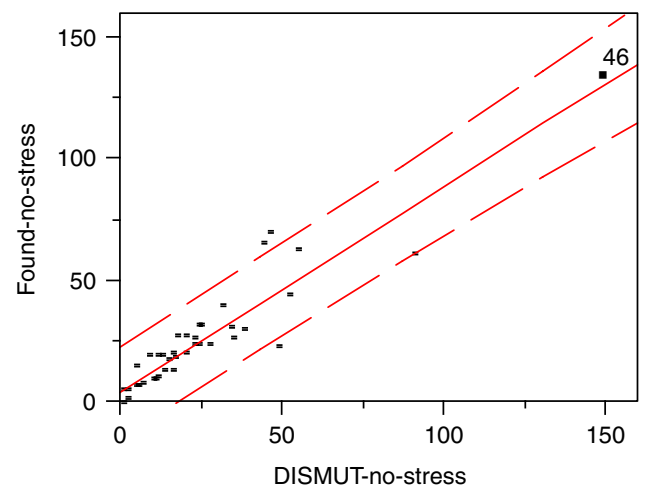

\section{Summary of Fit}

\begin{tabular}{lrrr}
$\mathrm{R}^{2}$ & & 0.873 & \\
$\mathrm{R}^{2}$ Adj & \multicolumn{2}{c}{0.869} & \\
Root Mean Square Error & \multicolumn{2}{c}{9.15} & \\
Mean of Response & 27.11 & \\
Observations & \multicolumn{2}{c}{} \\
Parameter Estimates & & & \\
Term & Estimate & Std Error & Prob>lt| \\
Intercept & 3.846 & 2.124 & 0.0788 \\
DISMUT no stress & 0.845 & 0.055 & $<.0001$
\end{tabular}

Fig. 2. Scatter plot of DISMUT model predictions against observations of the number of healthy/non-stressed trees in the sampled streets. Solid line denotes best fit, dashed lines denote the confidence $(p=0.1)$ range for individual estimates. where DISMUT estimates indicated at least some stressed trees were likely were significantly correlated with streets where reactive tree maintenance work was called for (Table 1). This correlation provides useful information to allow managers to anticipate the resources required for reactive maintenance. Poor growing conditions, including variable rainfall below the average for most of the last 10 years (Fig. 3), years may be responsible for the decreased number of healthy trees/increase in stressed or removed trees observed over the entire range of the sample, but this is not a likely reason for the larger crown dimensions observed.

The underestimate of the DISMUT predictions for canopy dimensions in the smaller diameter trees is substantial (more than $50 \%$ for trees less than $5 \mathrm{~m}$ crown diameter) but is not apparent in trees with a predicted diameter greater that about $12 \mathrm{~m}$ (Fig. 1b). The DISMUT system predicts tree dimensions by firstly modelling maximum height from age, then estimating crown dimensions from this height estimate (Banks et al., 1999). As the height estimates appear relatively reliable, the bias in the small crown estimates may be due to the simple form relating height to crown being inappropriate. Alternatively, younger and smaller crowned trees may have been able to take advantage of the above average rainfall in the recent couple of years and put on relatively more crown than the older trees.

The DISMUT census and models provide estimates over the entire public urban forest estate of maximum tree heights (unbiased), maximum canopy dimensions (biased) and number of healthy trees (biased) by street and park. The regressions developed (Figs. 1 and 2) can correct for the biases, but in practice, mean height and canopy may be more useful for estimation of urban forest values (Brack, 2002). Because we have a DISMUT estimate of the maximum value for every street and park in the city and expect a positive linear relationship between maximum tree dimensions predicted and mean tree dimensions observed, multi-phase sampling may be used to determine a statistically robust estimate of the true population mean. Fig. 4, for example, demonstrates that there is a significant relationship between DISMUT predictions of maximum crown dimension and the mean crown dimensions observed in the sampled streets. Regression sampling is the most appropriate two-phase sampling system in this case because the relationship between the auxiliary variable (DISMUT prediction) and variable of interest (crown width) is a straight line that does not go through the origin, but with errors that are homogeneous and normally distributed (Fig. 4).

DISMUT reports that the quadratic mean of all street maximum canopy predictions is $9 \mathrm{~m}$, which the regression in Fig. 4 estimates will correspond to a mean crown diameter of $8.2 \pm 0.8 \mathrm{~m}(p=0.05)$. Despite the bias in the 


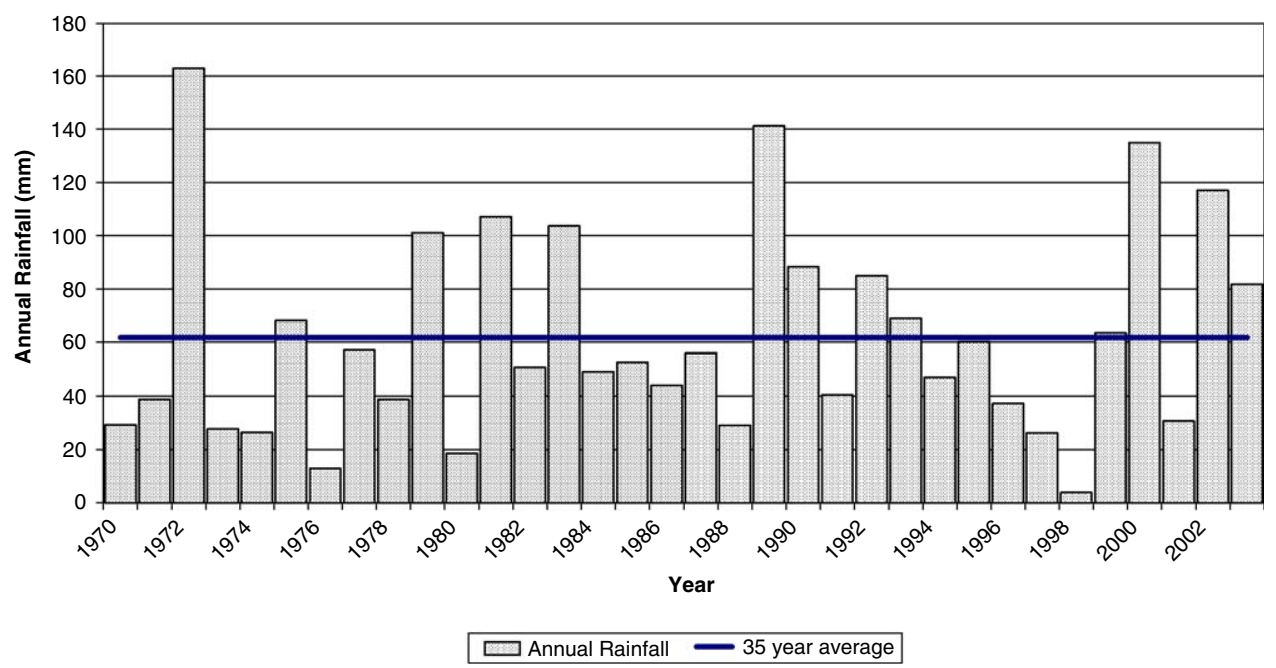

Fig. 3. Annual rainfall for a representative site in north Canberra. (Source: National Carbon Accounting Toolbox, http:// www.greenhouse.gov.au/ncas/ncat)

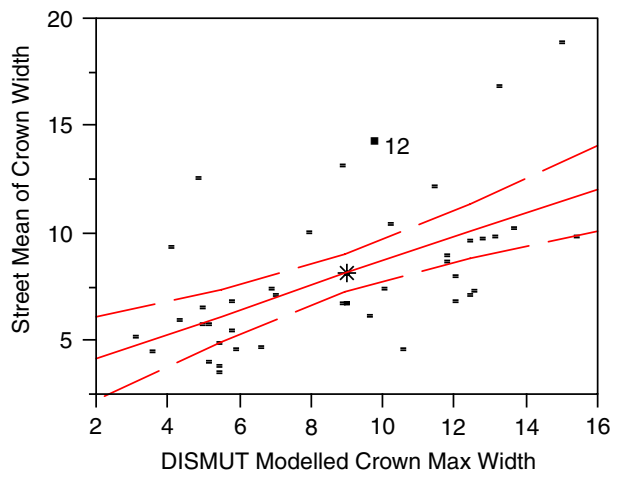

\section{Summary of Fit}

$\begin{array}{lr}R^{2} & 0.329 \\ R^{2} \text { Adj } & 0.313 \\ \text { Root Mean Square Error } & 2.811 \\ \text { Mean of Response } & 8.051 \\ \text { Observations } & 43\end{array}$

\section{Parameter Estimates}

$\begin{array}{lrrr}\text { Term } & \text { Estimate } & \text { Std Error } & \text { Prob }>|t| \\ \text { Intercept } & 3.081 & 1.188 & 0.0131 \\ \text { ModelledCrownMax } & 0.564 & 0.126 & <.0001\end{array}$

Fig. 4. Scatter plot of DISMUT model predictions of maximum crown width (auxiliary variable) against mean of crown width in the sampled streets. Solid line denotes best fit, dashed lines denote the confidence $(p=0.1)$ range for the line of best fit. * denotes the quadratic mean crown diameter of all DISMUT model predictions.

predictions of crown dimension by DISMUT, this correction is an unbiased estimate of the true mean crown diameter and can be used when calculating environmental, economic or social values that are related to crown area. Similarly, any variable that can be related to one or more of the DISMUT predictions can be estimated from a small sample to determine the regression parameters.

Few cities have detailed quantitative information on their urban forest assets (Nowak et al., 1996), and where they do, it often only a "point-in-time" estimate. Establishment of permanent growth points to provide information on growth and change is expensive and delays the estimation of change until at least two measurements are completed. The DISMUT approach of a complete census of basic but simply collected data and simple growth model forms allows for flexible projections of growth and change. These projections, applied to every street or park in the city, can be used for strategic level planning. For example, the original DISMUT models indicated that by 2020 , the majority of the trees in Canberra would reach a height in excess of $15 \mathrm{~m}$, which means that crown maintenance work after this date will become more expensive as different machinery would be required. A strategic decision to maximise any outstanding crown maintenance work prior to 2020 would therefore be likely to reduce the overall tree maintenance budget. Periodic samples, similar to this study, could cheaply monitor if the models are satisfactory, and whether the strategic planning is still appropriate. Also, provided there is at least some correlation, these periodic samples can be used to efficiently and objectively determine unbiased means of other parameters of interest.

\section{Conclusions}

The tree census and models developed for DISMUT can be used to reliably estimate the total size and condition of the urban forest estate in Canberra. 
Estimates were unbiased for height; however, estimates need to be adjusted for the decrease in the number of health trees observed. There may also be a need to adjust the form of the models that predict the crown dimensions, as they underestimate smaller trees. The existence of DISMUT projections for all streets and parks in the city also mean that statistically efficient approaches can be used to determine unbiased correction factors for the original predictions as well as expanding the inventory to estimate means for new population parameters of interest. The value of DISMUT to provide data for efficient multiphase sampling approaches will continue while ever there is a positive correlation between the DISMUT data and the parameters of interest. These useful correlations will probably continue until the original census data becomes obsolete due to substantial (non-recorded) plantings by leaseholders or wide-scale pest and disease outbreaks.

\section{Acknowledgement}

I am grateful for the help and funding received from Canberra Parks and Places (ACT Government) to undertake this work, and for permission to publish these results.

\section{References}

Banks, J.C.G., Brack, C.L., 2003. Canberra's Urban Forest: Evolution and planning for future landscapes. Urban Forestry and Urban Greening 1 (3), 151-160.

Banks, J.C.G., Brack, C.L., James, R.N., 1999. Modelling changes in dimensions, health status and arboricultural implications for urban trees. Urban Ecosystems 3 (1), 35-43.

Brack, C.L., 1997. Forest inventory in the 21st century. In: Proceedings of the Australian and New Zealand Institute of
Foresters Conference "Preparing for the 21st Century", 21-24 April 1997, Canberra, ACT, pp. 329-335.

Brack, C.L., 2002. Pollution mitigation and carbon sequestration by an urban forest. Environmental Pollution 116 (1), 195-200.

Brack, C.L., Banks, J.C.G., 2001. Planning for future streetscapes. In: Proceedings of the International Society of Arboriculture (Australia) Conference "Arboricultural Health", 11-12 October 2001, Canberra, Australia.

Brack, C.L., Banks, J.G., James, R.N., 1999a. Forestry out of the forests. In: Proceedings of the IFA Biennial Conference "Practising Forestry Today", Hobart, Tasmania 3-8 October, 1999, pp. 100-107.

Brack, C.L., James, R.N., Banks, J.G., 1999b. Data collection and management for tree assets in urban environments. In: Proceedings of the 21st Urban Data Management Symposium “UDMS'99". Venice, Italy, 21-23 April 1999, published on CD-ROM.

Chen, S.S., Jim, C.Y., 2003. Quantitative assessment of the treescape and cityscape of Nanjing, China. Landscape Ecology 18 (4), 395-412.

Jaenson, R., Bassuk, N., Schwager, S., Headley, D., 1992. A statistical method for the accurate and rapid sampling of urban street tree populations. Journal of Arboriculture 18, 171-183.

McPherson, E.G., Nowak, D., Heisler, G., Grimmond, S., Souch, C., Grant, R., Rowntree, R., 1997. Quantifying urban forest structure, function, and value: the Chicago Urban Forest Climate Project. Urban Ecosystems 1 (1), 49-61.

Miller, R.W., 1988. Urban Forestry, Planning and Managing Urban Green Spaces. Prentice-Hall, Englewood Cliffs, NJ (pp. 87).

Nowak, D.J., Rowntree, R.A., McPherson, E.G., Sisinni, S.M., Kerkmann, E.R., Stevens, J.C., 1996. Measuring and analyzing urban tree cover. Landscape and Urban Planning 36 (1), 49-57.

Nowak, D.J., Kuroda, M., Crane, D.E., 2004. Tree mortality rates and tree population projections in Baltimore, Maryland, USA. Urban Forestry and Urban Greening 2, 139-147. 